\title{
Joint inversion of teleseismic and InSAR datasets for the rupture process of the 2010 Yushu, China, earthquake
}

\author{
Yusuke Yokota, Yasuyuki Kawazoe*, Sunhe Yun ${ }^{\dagger}$, Satoko Oki, Yosuke Aoki, and Kazuki Koketsu \\ Earthquake Research Institute, University of Tokyo, Tokyo, Japan
}

(Received March 12, 2012; Revised April 10, 2012; Accepted April 16, 2012; Online published November 26, 2012)

\begin{abstract}
We have examined the rupture process of the 2010 Yushu, China, earthquake, which occurred in the eastern Tibetan plateau. Based on the results of centroid location grid searches, the aftershock distribution, and InSAR observations, we first constructed a left-lateral strike-slip bending fault model. We then carried out joint inversions of the teleseismic waveform data and InSAR data using various rupture front velocities. We obtained the optimum source model with a seismic moment of $2.3 \times 10^{19} \mathrm{~N} \mathrm{~m}\left(M_{\mathrm{w}} \sim 6.8\right)$, where the rupture velocity was found to be slightly faster than the shear wave velocity of the crust in this region. This supershear rupture velocity resulted in severe damage in and around the county seat of Yushu, which is located in the forward rupture direction of the source model. The features of this event, such as the shallow and fast rupture propagation may represent a seismic feature of the tectonic activity in the eastern Tibetan plateau.
\end{abstract}

Key words: Source process, InSAR data, fast rupture, joint inversion, tectonic activity.

\section{Introduction}

The 2010 Yushu, China, earthquake occurred at 7:49 a.m. on April 14 local time (11:49 p.m. on April 13 UT), 2010, in Yushu County, Yushu Tibetan Autonomous Prefecture, Qinghai Province, China, which is located in the eastern Tibetan plateau (ETP). The Global CMT Project (available at http://www.globalcmt.org/) reported the moment magnitude $\left(M_{\mathrm{w}}\right)$ and centroid depth to be 6.9 and $20 \mathrm{~km}$, respectively, indicating that this earthquake was a medium-sized crustal event. Yushu County suffered severe damage from this earthquake. The Xinhua News Agency reported that approximately 3000 people had died or were missing (available at http://english.news.cn/, 2010), which was larger than the several hundred estimated by USGS (http://earthquake.usgs.gov/earthquakes/ pager/events/us/2010vacp/index.html). The source characteristics of the earthquake were, at least in part, responsible for the large number of casualties.

The tectonic background of the ETP is complex owing to the collision of the Indian and Eurasian plates (e.g., He and Tsukuda, 2003). The detailed crustal deformation inside the ETP was also observed by GPS, so that the ETP can be sectionalized into the Qaidam, Kunlun, and Qiangtang blocks separated by the Kunlun and Manyi-YushuXianshuihe fault systems (Gan et al., 2007). Each block rotates clockwise relative to the Indian plate, at a rate which decreases toward the north. These block movements cause

\footnotetext{
*Now at Japan Meteorological Agency, Tokyo, Japan.

${ }^{\dagger}$ Now at ITOCHU Techno-Solutions Corporation, Tokyo, Japan.
}

Copyright (c) The Society of Geomagnetism and Earth, Planetary and Space Sciences (SGEPSS); The Seismological Society of Japan; The Volcanological Society of Japan; The Geodetic Society of Japan; The Japanese Society for Planetary Sciences; TERRAPUB

doi:10.5047/eps.2012.04.008 large earthquakes, such as the $1997 M_{\mathrm{w}} 7.5$ Manyi earthquake (Funning et al., 2007), the $2001 M_{\mathrm{w}} 7.8$ Central Kunlun earthquake (Lin et al., 2003), and the $2008 M_{\mathrm{w}} 7.9$ Wenchuan earthquake (Koketsu et al., 2010; Xu et al., 2010; Zhao et al., 2010). Their index moment magnitudes were determined by the Global CMT Project. The hypocenter of the 2010 Yushu earthquake was estimated to be near the Yushu fault by the USGS (latitude: $33.23^{\circ} \mathrm{N}$, longitude: $96.67^{\circ} \mathrm{E}$ ) and the China Earthquake Networks Center (latitude: $33.2^{\circ} \mathrm{N}$, longitude: $96.6^{\circ} \mathrm{E}$ ) (Fig. 1(a)). InSAR observations also show that this earthquake occurred along the Yushu fault (Fig. 1(b)). The Yushu fault is a northwestern part of the Manyi-Yushu-Xianshuihe fault system mentioned above. Therefore, its focal mechanism must reflect the interplay of the block movements and the resultant seismic activity in the ETP.

The source models of this earthquake were assumed using teleseismic data by Zhang et al. (2010) and other studies (the Yagi model; Y. Yagi, http://www.geol.tsukuba. ac.jp/yagi-y/EQ/20100414China/, 2010, and the Wang model; W. Wang, L. Zhao, and Z. Yao, http://www.csi. ac.cn/manage/html/4028861611c5c2ba0111c5c558b00001/ _content/10_04/14/1271250181605.html, 2010), and using InSAR data by Tobita et al. (2011). However, the features of these slip models are somewhat different from each other. In particular, Zhang et al. (2010) only suggested that this rupture propagated at a supershear speed. In the present study, we show the precise slip distribution and rupture propagation by a joint inversion of all available data, i.e., teleseismic and InSAR datasets.

We first determine the location of the centroid moment by the grid search method using $W$-phase and $P$-wave data. Next, we perform a joint inversion for the rupture process and assume the rupture velocity. Finally, we discuss the relevance of the inversion results to the severe damage and 


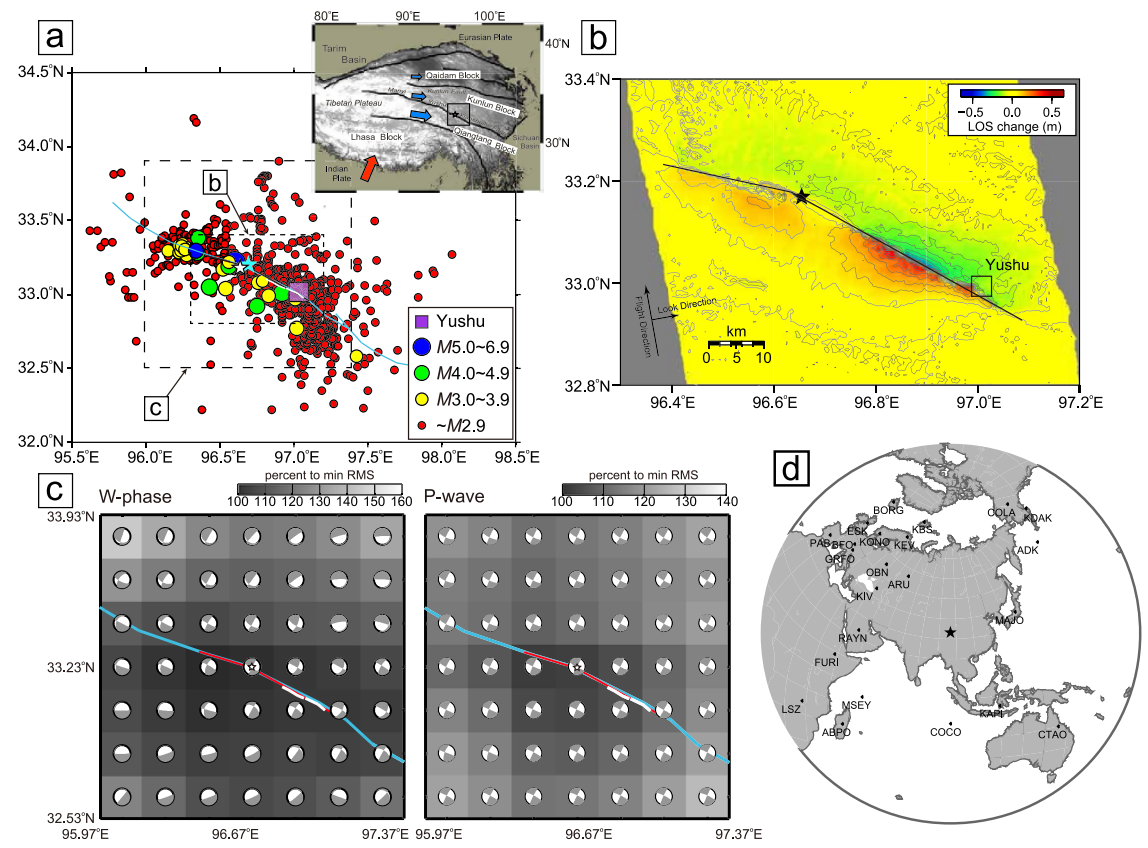

Fig. 1. (a) Distribution of aftershocks (circles) determined by the China Earthquake Networks Center. The light blue and white stars indicate the hypocenters determined by the USGS and the China Earthquake Networks Center, respectively. The solid black line indicates the fault model of the mainshock. The light-blue and white lines indicate the Manyi-Yushu-Xianshuihe fault and the observed surface rupture trace shown in Chen et al. (2010) and Lin et al. (2011). The purple square indicates the county seat of Yushu. (b) The deformation field caused by the 2010 Yushu earthquake. The flight and line-of sight directions are also shown in the panel. The black line and star indicate the fault model and hypocenter used in this study. (c) Results of the $W$-phase (left) and $P$-wave (right) centroid location grid searches. Inverted grids are colored by their misfit percentage relative to the minimum RMS value. The best-fitting solution is shown with a star. Red, light-blue, and white lines indicate the fault model, the Manyi-Yushu-Xianshuihe fault, and the surface rupture trace, respectively. (d) Stations observing the teleseismic seismograms used in this study.
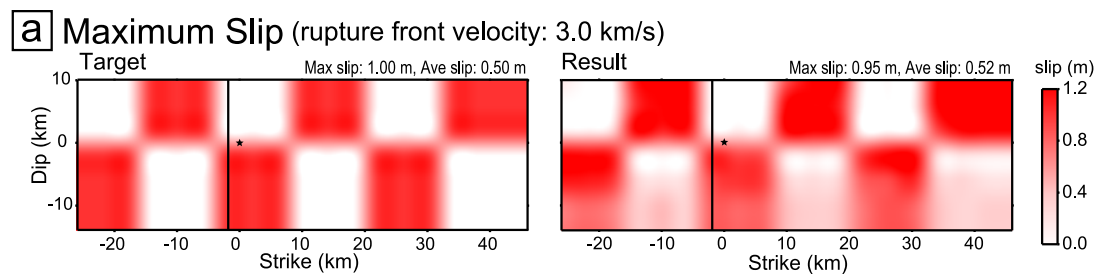

b Rupture Front Velocity (input slip: $1.0 \mathrm{~m}$ )
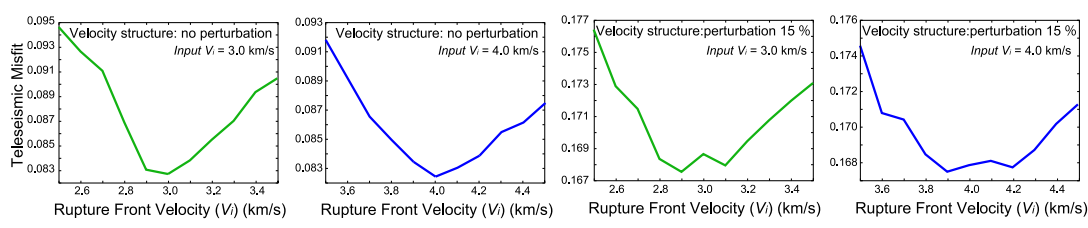

Fig. 2. (a) Target model used for the checkerboard resolution test (left: slips of $0 \mathrm{~m}$ and $1.0 \mathrm{~m}$ on an alternating group of $3 \times 3$ subfaults), and the result of the checkerboard resolution test for the joint inversion (right). (b) Variations in misfit as a function of rupture front velocity $\left(V_{i}\right)$ by the synthetic tests in the models where the true $V_{i}=3.0$ (leftmost) or $4.0 \mathrm{~km} / \mathrm{s}$ (second left), and additionally using the velocity structure model with a perturbation of $15 \%$ in the models where the true $V_{i}=3.0$ (second right) or $4.0 \mathrm{~km} / \mathrm{s}$ (rightmost).

the tectonic activity in the ETP.

\section{Centroid Location Grid Search}

We first searched for the location of the centroid moment using the grid search method around the Yushu fault. This grid search was performed on a grid with a spacing of $0.2^{\circ}$ at a depth of $10 \mathrm{~km}$. We used the two point source inversion methods of $W$-phase and $P$-wave waveforms developed by Kanamori and Rivera (2008) and Kikuchi and Kanamori (1991), respectively. The $W$-phase and $P$-wave parts of the teleseismic waveform data from the IRIS DMC were filtered with passbands of $0.002-0.01 \mathrm{~Hz}$ and $0.02-$ $0.5 \mathrm{~Hz}$, respectively. Figure 1(c) shows the solutions and the misfit percentages on the grids. Each best-fitting solution is located not around the surface rupture trace (Chen $e t$ al., 2010; Lin et al., 2011) but in the vicinity of the USGS hypocenter.

We obtained two point source solutions from the above grid searches. The strike, dip, and rake in the first solution from the $W$-phase grid search are $119^{\circ}, 72^{\circ}$, and $3^{\circ}$, 


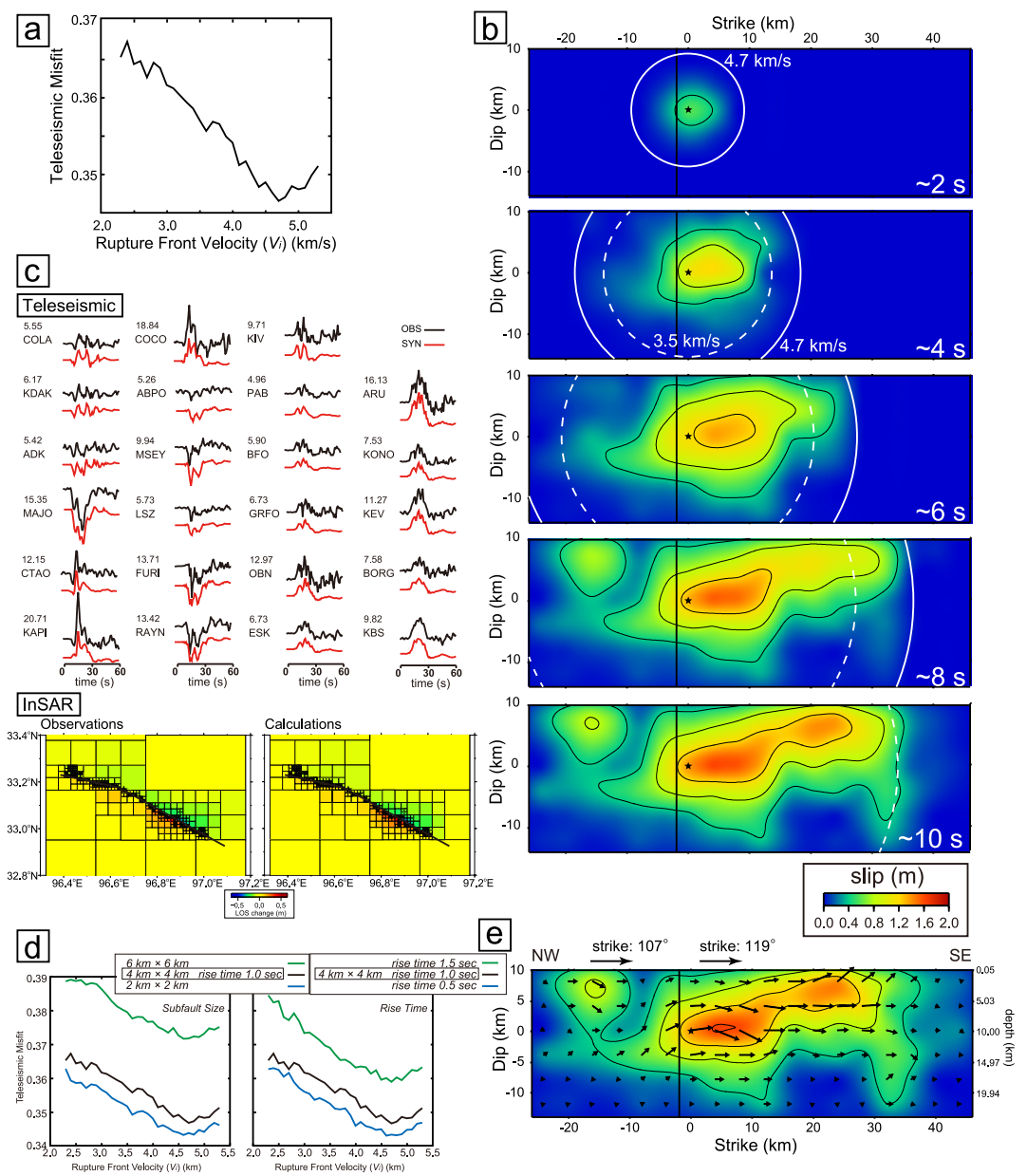

Fig. 3. (a) Variations in teleseismic misfit as a function of rupture front velocity $\left(V_{i}\right)$. (b) Snapshots of the slip distribution of the best-fitting model. Solid and dashed white circles indicate rupture propagation at speeds of 4.7 and $3.5 \mathrm{~km} / \mathrm{s}$. (c) (upper) Comparison of the observed and synthetic waveforms from the joint inversion. The number above the station code denotes the peak-to-peak value of the observed record in micrometers, whereas the number below the station code is the station azimuth measured from the source. (lower) Comparison of the InSAR LOS observations and the calculations from the joint inversion in quadtree blocks. (d) Variations in misfit as a function of rupture front velocity $\left(V_{i}\right)$ in models using other subfault sizes (left) and rise times (right). (e) Resultant slip distribution obtained by the finite source inversion using the teleseismic waveform data and InSAR data. The black star and arrows indicate the hypocenter and the subfault slips on the hanging wall, respectively.

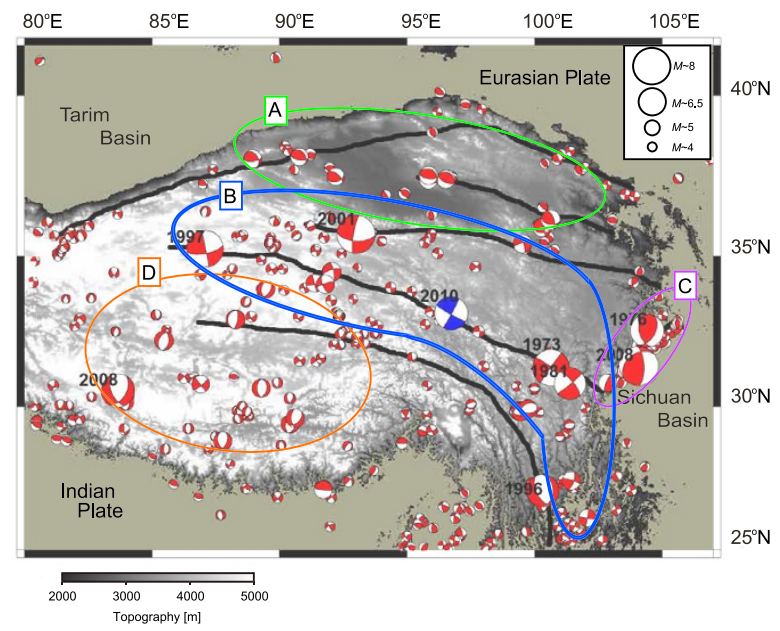

Fig. 4. Map of the ETP showing the $1973 M_{\mathrm{S}} 7.5$ (Zhou et al., 1983) and $1981 M_{\mathrm{w}} 6.5$ earthquakes along the Xianshuihe fault, the $1976 M_{\mathrm{w}} 6.7$ Sichuan Province earthquake, the $1996 M_{\mathrm{w}} 6.6$ Yunnan Province earthquake, the $1997 M_{\mathrm{w}} 7.5$ Manyi earthquake, the $2001 M_{\mathrm{w}} 7.8$ Central Kunlun earthquake, the $2008 M_{\mathrm{w}} 7.9$ Wenchuan earthquake, the $2008 M_{\mathrm{w}} 6.7$ Xizang earthquake, the $2010 M_{\mathrm{w}} 6.9$ Yushu earthquake, and $4.0 \leq M_{\mathrm{w}} \leq 6.5$ earthquakes from 1976 to 2010, determined by the Global CMT Project. These earthquakes are categorized into zones A, B, C, and D according to their locality. The black solid lines indicate principal active fault systems. 
respectively, whereas those in the second solution from the $P$-wave grid search are $119^{\circ}, 84^{\circ}$, and $3^{\circ}$. Therefore, both solutions suggest an overall focal mechanism of left-lateral strike slip on a near-vertical fault plane and an $M_{\mathrm{w}}$ of $6.8 \sim$ 6.9 , which is similar to the solution obtained by the Global CMT Project (2010).

\section{Joint Inversion}

Next, we performed a joint inversion of the teleseismic and InSAR data using the method of Yoshida et al. (1996) with the revisions of Hikima and Koketsu (2005). Based on the grid searches and InSAR data (Fig. 1(b)), we determined the hypocenter as (latitude: $33.18^{\circ} \mathrm{N}$, longitude: $96.65^{\circ} \mathrm{E}$, depth: $10 \mathrm{~km}$ below ground surface). In addition, based on the aftershock distribution determined by the China Earthquake Networks Center (available at http://www.csndmc.ac.cn/newweb/ large_quakes/qinghai2010/qinghai.htm, 2010; Fig. 1(a)), we constructed a $72 \mathrm{~km} \times 24 \mathrm{~km}$ fault model with a dip of $84^{\circ}$. This fault model was divided into 108 subfaults of 4 $\mathrm{km} \times 4 \mathrm{~km}$. The strikes of these subfaults were set to $107^{\circ}$ and $119^{\circ}$ in the western six columns and the eastern twelve columns, respectively. Strike-slip vectors, represented by linear combinations of two components in the directions of $0^{\circ} \pm 45^{\circ}$, were placed at the centers of the subfaults. Ten triangle functions with a rise time of $1.0 \mathrm{~s}$ were used as the temporal basis functions for ten time windows at each subfault.

We then prepared the teleseismic and InSAR datasets. We used the 60-s-long $P$-wave parts of the teleseismic waveform data filtered with a passband of $0.02-0.5 \mathrm{~Hz}$. Considering the data quality and the azimuthal coverage, we chose the waveforms observed at 23 stations with epicentral distances between $30^{\circ}$ and $100^{\circ}$ (Fig. 1(d)). The interferogram data (Fig. 1(b)) were acquired on 15 January, 2010, and 17 April, 2010. For the inversion, we resampled this data using a quadtree decomposition method (Jonsson et al., 2002).

For the teleseismic dataset, the Green's functions were computed using the method of Kikuchi and Kanamori (1991), which includes an extension to reflect the velocity structures near the source and stations. For the InSAR dataset, the Green's functions were computed using the method of Zhu and Rivera (2002). We adopted the CRUST 2.0 model by Laske, Masters, and Reif (available at http://igppweb.ucsd.edu/ gabi/crust2.html) for deriving these velocity structures and applied the rigidity based on this model.

Finally, we performed the finite source inversion for inferring the rupture process of the 2010 Yushu earthquake. In order to stabilize the inversion, we used a smoothness constraint of the slip distribution with a discrete Laplacian in space, and the weight of the constraint was determined by minimizing Akaike's Bayesian Information Criterion (ABIC) (Akaike, 1980). The weight for each dataset was applied so that the datasets were equally weighted.

We preliminarily examined the resolution of this model by means of a checkerboard test. We generated synthetic datasets for the checkerboard-like slip distributions shown in Fig. 2(a). These synthetic datasets were inverted using the same parameters as this joint inversion described in the latter paragraph. We confirmed that this inversion model has a resolution that can adequately calculate slip distribution and slip value (Fig. 2(a)). Next, we tried various rupture front velocities $\left(V_{i}\right)$ which give the first time window at each subfault, in slip models where $V_{i}=3.0$ or $4.0 \mathrm{~km} / \mathrm{s}$. Additionally, we performed synthetic tests using the velocity structure model with a perturbation of $15 \%$, as shown in Fig. 2(b). These results show that our inversion has a sufficient resolution to determine the best-fitting rupture front velocity of the order of $0.2 \mathrm{~km} / \mathrm{s}$ swing.

We found that $V_{i}=4.7 \mathrm{~km} / \mathrm{s}$ yielded the smallest normalized misfit between the observed and synthetic waveforms (Fig. 3(a)). To see the rupture velocity, Fig. 3(b) shows inferred snapshots of the slip distribution of the bestfitting model. These snapshots show that the rupture first propagated at the rate of $2.5-3.5 \mathrm{~km} / \mathrm{s}$, and then slightly faster than the $S$-wave velocity $\left(V_{S}\right)$ of the crustal part of the near-source velocity structure $(3.5 \mathrm{~km} / \mathrm{s})$, which indicates supershear rupture as was assumed by Zhang et al. (2010). The synthetic teleseismic waveforms and surface dislocations for this result are in good agreement with the observations, as shown in Fig. 3(c). The result also indicates the overall features of the earthquake, such as the total seismic moment of $2.3 \times 10^{19} \mathrm{~N} \mathrm{~m}$, which corresponds to an $M_{\mathrm{w}}$ of 6.8 , and a maximum slip of approximately $1.6 \mathrm{~m}$. We tried other subfault sizes and rise times of time windows to examine the model's dependence on the rupture front velocity. Figure 3(d) compares variations in misfit in several models. These results suggest that the best-fitting rupture front velocity is not strongly affected by these model parameters.

Figure 3(e) shows the resultant slip distribution. There is a large slip area in the neighborhood of the hypocenter, which is consistent with the results of the grid searches. This slip area spans $30 \mathrm{~km}$ to the southeast and extends to the surface. This resultant slip value and slip distribution are consistent with a source model assumed by Tobita $e t$ al. (2011) using the InSAR data only.

This shallow slip area caused strong ground motions in and around the earthquake source region. Those to the southeast were further enhanced due to the rupture directivity effect (e.g., Koketsu and Miyake, 2008). In particular, in cases of supershear rupture propagation, such as in the 2010 Yushu earthquake, the large $S$-wave energy is radiated around the rupture front (Dunham and Archuleta, 2005; Dunham and Bhat, 2008). Since the county seat of Yushu is located around this rupture front, as shown in Fig. 1(a), the supershear rupture propagation may be one reason for the severe damage from the earthquake.

\section{Relation to Tectonic Activity}

The inversion result indicates that this earthquake occurred with a left-lateral strike-slip faulting mechanism. To categorize this earthquake among the earthquakes in the ETP, we have plotted, in Fig. 4, the focal mechanisms of all $M_{\mathrm{w}} \geq 4$ earthquakes which occurred from 1973 to April 2010. All the earthquakes were divided into four zones according to their locality, as shown in Fig. 4. In zone $\mathrm{A}$, along the northern ridge region of the ETP, many re- 
verse dip-slip earthquakes were generated by the collision of the ETP and the Eurasian plate. In zone B, around the Kunlun and Xianshuihe faults, several $M_{\mathrm{w}} \geq 6.5$ strikeslip earthquakes were generated along the main active fault systems. These mechanisms reflect the different rotation rates of the blocks. Many smaller earthquakes also occurred with strike-slip faulting mechanisms in this zone. The collision of the Kunlun block and the Sichuan basin in the easternmost part of the ETP (zone C) generated reverse dipslip earthquakes, such as the 2008 Wenchuan earthquake. Accordingly, a considerable number of $M_{\mathrm{w}} \geq 6.5$ class earthquakes were generated in zones B and C. In zone D, near the Himalaya mountains, most earthquakes occurred through the normal faulting mechanism. These earthquakes were apparently generated by the bending and migration of crustal blocks at a high altitude (e.g., Tapponnier et al., 1981). The 2010 Yushu earthquake is located in zone B, and its focal mechanism is consistent with the seismic features of the tectonic activity in this zone, as mentioned above.

When the accumulated strain in a bonded region reaches its maximum, an earthquake occurs. Therefore, in zone $\mathrm{B}$, large earthquakes were generated repeatedly in bonded regions. An event close to the Yushu fault occurred in 1738 (Chen et al., 2010). Because the average rate of the relative motion along the Yushu fault is about $7 \mathrm{~mm} / \mathrm{yr}$ (Zhou et al., 1997), the total accumulated movement from 1738 along the Yushu fault can be assumed to be about $1.9 \mathrm{~m}$. Our resultant slip is consistent with this value. Using the InSAR data only, Tobita et al. (2011) showed that their resultant maximum slip was also in agreement with this value. From these results, the recurrence interval of this repeating earthquake is about 300 years.

In zone $\mathrm{B}$, the shallow and supershear rupture propagation was observed during the 2001 Central Kunlun earthquake (Bouchon and Vallee, 2003; Lin et al., 2003). Koketsu et al. (2010) also observed the near-shear rupture propagation during the 2008 Wenchuan earthquake in zone C. Even in the case of this earthquake, a shallow rupture propagation was assumed (Koketsu et al., 2010; Xu et al., 2010; Zhao et al., 2010). Our results suggest that the 2010 Yushu earthquake had features similar to these earthquakes. These kinds of rupture propagation may represent a seismic feature of the tectonic activity in the ETP.

\section{Conclusions}

We have examined the rupture process of the 2010 Yushu earthquake by the joint inversion of teleseismic and InSAR datasets. The obtained inversion results suggest that the rupture directivity effect and supershear rupture propagation caused the severe damage in Yushu County. These results are also consistent with the tectonic activity in the ETP, exhibiting the seismic features of zones B and C, such as shallow and fast rupture propagation. These features may enhance seismic damage in this region.

Acknowledgments. We thank Dr. Eric M. Dunham and an anonymous reviewer for their helpful comments. The teleseismic waveform data and information on the earthquakes and aftershocks were provided by the IRIS DMC, Global CMT Project, USGS, and China Earthquake Networks Center.

\section{References}

Akaike, H., Likelihood and Bayes procedure, in Bayesian Statistics, edited by L. Bernardo et al., pp. 143-166, Univ. Press, Valencia, Spain, 1980. Bouchon, M. and M. Vallee, Observation of long supershear rupture during the magnitude 8.1 Kunlunshan earthquake, Science, 301, 824-826, 2003.

Chen, L. et al., The $M_{S} 7.1$ Yushu earthquake surface ruptures and historical earthquakes, Chin. Sci. Bull., 13, 1200-1205, 2010.

Dunham, E. and R. Archuleta, Near-source ground motion from steady state dynamic rupture pulses, Geophys. Res. Lett., 32, L03302, 2005.

Dunham, E. and H. Bhat, Attenuation of radiated ground motion and stresses from three-dimensional supershear ruptures, J. Geophys. Res., 113, B08319, 2008.

Funning, G., B. Parsons, and T. Wright, Fault slip in the 1997 Manyi, Tibet earthquake from linear elastic modelling of InSAR displacements, Geophys. J. Int., 169, 988-1008, 2007.

Gan, W. et al., Present-day crustal motion within the Tibetan Plateau inferred from GPS measurements, J. Geophys. Res., 112, B08416, 2007.

He, H. and E. Tsukuda, Recent progresses active fault research in China, J. Geogr., 112(4), 489-520, 2003.

Hikima, K. and K. Koketsu, Rupture processes of the 2004 Chuetsu (midNiigata prefecture) earthquake, Japan: A series of events in a complex fault system, Geophys. Res. Lett., 32, L18303, 2005.

Jonsson, S., H. Zebker, P. Segall, and F. Amelung, Fault slip distribution of the $1999 \mathrm{Mw} 7.1$ Hector Mine, California, earthquake, estimated from satellite radar and GPS measurements, Bull. Seismol. Soc. Am., 92, 1377-1389, 2002.

Kanamori, H. and L. Rivera, Source inversion of W phase: speeding up seismic tsunami warning, Geophys. J. Int., 175, 222-238, 2008.

Kikuchi, M. and H. Kanamori, Inversion of complex body waves. III, Bull. Seismol. Soc. Am., 81, 2335-2350, 1991.

Koketsu, K. and H. Miyake, A seismological overview of long-period ground motion, J. Seismol., 12, 133-143, 2008.

Koketsu, K., K. Hikima, Y. Yokota, and Z. Wang, Joint inversion of teleseismic and strong motion data for the rupture process of the 2008 Wenchuan, China, earthquake, EGU General Assembly 2010, EGU2010-7992, 2010.

Lin, A., M. Kikuchi, and B. Fu, Rupture segmentation and process of the 2001 Mw 7.8 Central Kunlun, China, earthquake, Bull. Seismol. Soc. Am., 84, 2477-2492, 2003.

Lin, A., G. Rao, D. Jia, X. Wu, B. Yan, and Z. Ren, Co-seismic strike-slip surface rupture and displacement produced by the $2010 \mathrm{Mw} 6.9$ Yushu earthquake, China, and implications for Tibetan tectonics, J. Geodyn., 52, 249-259, 2011.

Tapponnier, P., J. Mercier, R. Armijo, H. Tonglin, and Z. Ji, Field evidence for active normal faulting in Tibet, Nature, 294, 410-414, 1981.

Tobita, M., T. Nishimura, T. Kobayashi, K. Hao, and Y. Shindo, Estimation of coseismic deformation and a fault model of the 2010 Yushu earthquake using PALSAR interferometry data, Earth Planet. Sci. Lett., 307, 430-438, 2011.

Xu, C., Y. Liu, Y. Wen, and R. Wang, Coseismic slip distribution of the $2008 \mathrm{Mw} 7.9$ Wenchuan earthquake from joint inversion of GPS and InSAR data, Bull. Seismol. Soc. Am., 100(5B), 2736-2749, 2010.

Yoshida, S., K. Koketsu, B. Shibazaki, T. Sagiya, T. Kato, and Y. Yoshida, Joint inversion of near- and far-field waveforms and geodetic data for the rupture process of the 1995 Kobe earthquake, J. Phys. Earth, 44, 437-454, 1996.

Zhang, Y., L. Xu, and Y. Chen, Source process of the 2010 Yushu, Qinghai, earthquake, Sci. China Earth Sci., 53, 1249-1251, 2010.

Zhao, C., Z. Chen, L. Zhou, Z. Li, and Y. Kan, Rupture process of the Wenchuan M8.0 earthquake of Sichuan, China: the segmentation feature, Chinese Sci. Bull., 55, 284-292, 2010.

Zhou, H., H. Liu, and H. Kanamori, Source process of large earthquakes along the Xianshuihe fault in southwestern China, Bull. Seismol. Soc. Am., 73, 537-551, 1983.

Zhou, R., S. Ma, and C. Cai, Late Quaternary active features of the GanziYushu fault zone, Earthq. Res. China, 12, 250-260, 1997 (in Chinese with English abstract).

Zhu, L. and L. Rivera, A note on the dynamic and static displacements from a point source in multilayered media, Geophys. J. Int., 148, 619627, 2002.

Y. Yokota (e-mail: yusuke@eri.u-tokyo.ac.jp), Y. Kawazoe, S. Yun, S. Oki, Y. Aoki, and K. Koketsu 